\title{
Mitral regurgitation determined by radionuclide cardiography: dependence on posture and exercise
}

\author{
Henning Kelbæk, Jan Aldershvile, Knud Skagen, Per Hildebrandt, Steen Levin Nielsen
}

\begin{abstract}
Objectives-To evaluate dependence of posture and exercise on the degree of mitral regurgitation using combined first pass and equilibrium radionuclide cardiography.

Design-24 patients with clinically stable chronic mitral regurgitation and sinus rhythm were studied by first pass list mode and simultaneous multigated frame mode equilibrium radionuclide cardiography using red cells labelled with technetium-99m.

Results-When patients changed posture from supine to sitting upright, left ventricular volumes decreased considerably. Regurgitation tended to increase in patients with valve prolapse but decreased in patients with ischaemic heart disease and dilated cardiomyopathy. During submaximal bicycle exercise cardiac output increased without dilatation of the left ventricle. The increase in left ventricular forward stroke volume was more pronounced than that in the total stroke volume, leading to a considerable decrease in the regurgitant flow through the mitral valve. The repeatability and observer variability of radionuclide determination of regurgitation was acceptable, with limits of agreement within about $10 \%$.
\end{abstract}

Conclusions-Change in posture induces a normal haemodynamic response in most patients with chronic mitral regurgitation; the effect of posture on regurgitation depends on the underlying disease. Mild to moderate exercise causes no deterioration in the severity of regurgitation.

(Br Heart f 1994;72:156-160)

Recent reports emphasise the difficulty in determining the best time for surgery in patients with mitral regurgitation ${ }^{12}$ and the importance of developing non-invasive techniques to monitor the course of the disorder. ${ }^{34}$ A non-invasive radionuclide method measuring the severity of mitral regurgitation was recently shown to correlate well with semiquantitative measures derived from invasive contrast ventriculography. ${ }^{5}$ This technique combines the first pass technique measuring the forward (functional) stroke volume and the equilibrium technique measuring the total (absolute) stroke volume. When identical corrections for background activity originating from these stroke volumes are used a major weakness of radionuclide cardiography is diminished and the validity of the technique is thereby increased. ${ }^{5}$

Examinations of cardiac disorders are conventionally performed under standardised conditions with the subject supine and thus do not reflect the disease state during daily activities. We evaluated the impact of posture and exercise on the severity of regurgitation in patients with chronic mitral valve disease. We also evaluated the reproducibility of the radionuclide technique in terms of variation over time and with observer.

\section{Patients and methods}

STUDY PROTOCOL

To evaluate the impact of posture on mitral regurgitation 18 patients were examined on the same day while sitting at $60^{\circ}$ and while lying supine. Half of the patients were randomly allocated to have the examinations in the upright position performed first.

Ten patients were examined upright at rest and during bicycle exercise to determine the influence of physical stress on the severity of the disease.

The reproducibility of the radionuclide technique was evaluated in two ways. Hour to hour variation was measured by examining 13 supine patients twice on the same day, the examinations being one hour apart. Day to day variation was measured by examining 14 patients twice, the examinations being two weeks apart. In addition, data from 20 patients were stored and processed by two independent observers.

Exercise was performed on an ergometer bicycle, and the workload was progressively adjusted with increments of $25 \mathrm{~W}$ every two minutes until the heart rate was increased by $35-40 \%$ compared with the value at rest. No attempt was made to provoke cardiac symptoms during exercise. Data were collected one minute after attaining the highest workload which was maintained for up to 10 minutes. All patients gave their informed consent, and the study protocol was approved by the local ethics committee.

PATIENTS

We studied 24 patients (14 men and 10 women, aged 27 to 82 (mean 59)) with moderate to severe chronic mitral valve regurgitation as judged from the results of contrast ventriculography or Doppler echocardio- 
Table 1 Mean (SD) values of haemodynamic variables, in supine and upright positions in 18 patients with mitral regurgitation.

\begin{tabular}{|c|c|c|c|}
\hline & Supine & Upright & $\begin{array}{l}95 \% \text { Confidence interval } \\
\text { for difference upright - supine }\end{array}$ \\
\hline Heart rate (beats $/ \mathrm{min}$ ) & $72(14)$ & $76(14)$ & 1 to 6 \\
\hline $\begin{array}{l}\text { Blood pressure (mm Hg): } \\
\text { Systolic }\end{array}$ & $126(19)$ & 127 (21) & -2 to 3 \\
\hline Diastolic & $78(7)$ & $84(8)$ & 3 to 9 \\
\hline $\begin{array}{l}\text { Left ventricular ejection } \\
\text { fraction }(\%)\end{array}$ & $58(18)$ & 60 (18) & 0 to 4 \\
\hline $\begin{array}{l}\text { Total stroke volume }(\mathrm{ml}) \\
\text { Regurgitant volume (ml) }\end{array}$ & $\begin{array}{r}132(60) \\
70(52)\end{array}$ & $\begin{array}{r}109(42) \\
57(41)\end{array}$ & $\begin{array}{l}-36 \text { to }-10 \\
-25 \text { to }-1\end{array}$ \\
\hline $\begin{array}{l}\text { Regurgitation fraction (\%): } \\
\text { Patients with mitral prolapse } \\
\text { and chorda rupture }\end{array}$ & $52(19)$ & $57(15)$ & -1 to 12 \\
\hline $\begin{array}{l}\text { Patients with secondary mitral } \\
\text { regurgitation }\end{array}$ & $27(12)$ & $12(11)$ & -24 to -5 \\
\hline Whole group & $43(22)$ & $43(25)$ & -7 to 7 \\
\hline
\end{tabular}
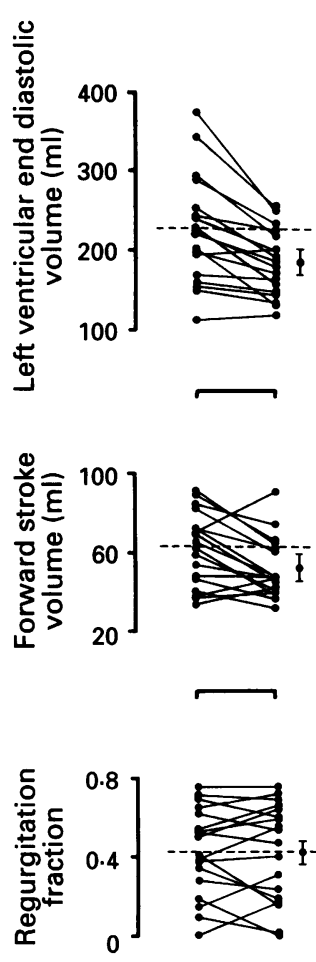

Supine Upright

Figure 1 Left ventricular end diastolic volume, forward stroke volume, and regurgitation fraction in supine and upright positions in 18 patients with mitral regurgitation. Dashed lines indicate mean baseline values and bars $95 \%$ confidence intervals for differences. graphy. Ten patients had mitral valve prolapse, six ischaemic heart disease, three rheumatic valve disease, two ruptured chordae (primarily valve prolapse), two previous endocarditis, and two dilatated cardiomyopathy. The patients' conditions were clinically stable (New York Heart Association classification groups I and II). For technical reasons (see below) only patients with sinus rhythm were included. Reasons for exclusion were pregnancy, lactation, left sided cardiac valve disease other than mitral valve regurgitation, and treatment with vasodilatory drugs.

\section{INVESTIGATIONS}

Heart rate was measured in a three lead electrocardiogram, and blood pressure was recorded sphygmomanometrically.

Radionuclide cardiography was performed by a combined first pass and multigated equilibrium technique after in vitro labelling of autologous red blood cells with technetium$99 \mathrm{~m} .{ }^{6}$ To determine the cardiac output from a bolus transit curve, roughly $500 \mathrm{MBq}$ (14 $\mathrm{mCi}$ ) was injected through a cannula in the right basilic vein for each investigation. First pass data were acquired in list mode in a $256 \times 256$ matrix with a mobile gammacamera equipped with a low energy all purpose collimator (Siemens) in the left anterior oblique projection; data were processed in a $128 \times 128$ frame format by means of a dedicated computer. A 10 second static image was acquired in the same format with simultaneous drawing of a blood sample to determine the activity in blood after complete mixing of the tracer. ${ }^{7}$ Multigated equilibrium cardiography was performed in the same projection in a $64 \times 64$ matrix and a duration of 16 frames per cardiac cycle. ${ }^{8}$

Forward stroke volume was calculated as the activity recorded in the left ventricular region of interest multiplied by the tracer distribution volume and divided by the product of the area under the time activity curve in the same region and the heart rate. ${ }^{7}$

The left ventricular ejection fraction was determined as 1 - the end systolic activity divided by end diastolic activity; the left ventricular end diastolic volume was calculated as the end diastolic frame activity corrected for specific blood activity and attenuation. The total (absolute) stroke volume was determined as the product of the left ventricular end diastolic volume and ejection fraction as assessed by the equilibrium method. ${ }^{9}$

The regurgitant volume was calculated as the difference between the total and the forward stroke volume, and the regurgitation fraction was calculated as the regurgitant volume divided by the total stroke volume. ${ }^{5}$

\section{STATISTICAL ANALYSIS}

Data from the investigations performed while the patient was upright and supine and from those performed while the patient was resting and exercising were processed by one observer and evaluated from the $95 \%$ confidence intervals of the differences. ${ }^{1011}$

Repeat investigations performed to assess the hour to hour and day to day variation were also processed by one person, but two independent observers evaluated the data to determine the observer variation of the radionuclide technique. Owing to limited capacity of data storing, measurements of observer variation were restricted to data obtained while patients were supine. Repeatability and observer variation were evaluated by comparison of the difference against mean method described previously. ${ }^{1112}$ The limits of agreement were expressed as 1.96 standard deviations of the differences between the two determinations.

\section{Results}

POSTURE DEPENDENT HAEMODYNAMIC

CHANGES

From the supine to the upright position heart rate increased by $6 \%$ and diastolic blood pressure by $8 \%$ (table 1 ). The mean left ventricular volume decreased at end diastole from $228 \mathrm{ml}$ to $185 \mathrm{ml}$ ( $95 \%$ confidence interval for the difference -60 to $-25 \mathrm{ml}$ ), with a concomitant $17 \%$ reduction in the total stroke volume (table 1 and fig 1). The volume changes were independent of left ventricular size. No change was recorded in the left ventricular ejection fraction. While patients were upright the mean forward stroke volume was reduced from $63 \mathrm{ml}$ to $53 \mathrm{ml}$ ( -18 to $-4 \mathrm{ml})$ compared with that recorded while they were supine. The decrease in the regurgitant volume was similar to the change in total stroke volume, leaving the regurgitation fraction for the whole group unaltered. Patients with mitral valve prolapse and ruptured chordae alone, however, tended to show increased regurgitation when they were upright, whereas patients with secondary mitral regurgitation due to ischaemic heart disease or dilated cardiomyopathy showed significantly less regurgitation when they sat up (table 1 and fig 1 ).

EXERCISE INDUCED HAEMODYNAMIC CHANGES The exercise induced increases in heart rate and systolic blood pressure were $37 \%$ and $17 \%$, respectively, compared with the values at rest (table 2). No significant change occurred in left ventricular end diastolic volume, whereas small increments were seen in both total stroke volume and left ventricular 
Table 2 Mean (SD) values of haemodynamic variables at rest and during submaximal bicycle exercise in 10 patients with mitral regurgitation

\begin{tabular}{lrrc}
\hline & Rest & Exercise & $\begin{array}{l}\text { 95\% Confidence interval } \\
\text { for difference (exercise }- \text { rest) }\end{array}$ \\
\hline Heart rate (beats/min) & $82(13)$ & $112(11)$ & 23 to 38 \\
Blood pressure (mm Hg): & & & \\
$\quad$ Systolic & $128(23)$ & $150(18)$ & 13 to 30 \\
$\quad$ Diastolic & $84(10)$ & $83(15)$ & -6 to 5 \\
Left ventricular ejection fraction (\%) & $68(12)$ & $70(12)$ & 0 to 4 \\
Total stroke volume (ml) & $109(41)$ & $115(38)$ & 1 to 12 \\
Regurgitant volume (ml) & $64(38)$ & $48(40)$ & -31 to -2 \\
\hline
\end{tabular}

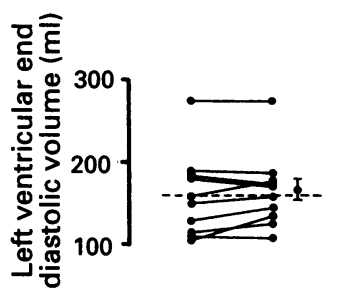

ejection fraction (table 2 and fig 2). A more pronounced increase of $26 \%$ ( $13 \%$ to $40 \%$ ) was recorded in the forward stroke volume (fig 2), resulting in a considerable reduction in the regurgitant volume (table 2) and a $24 \%$ decrease $(-38 \%$ to $-10 \%)$ in regurgitation fraction during exercise (fig 2 ).

\section{REPRODUCIBILITY OF RADIONUCLIDE}

TECHNIQUE

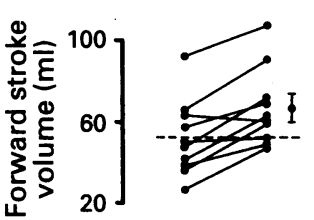

Haemodynamic variables at rest lying down determined by the combined radionuclide technique after an hour and after 14 days showed high levels of reproducibility with no significant differences between the two determinations (table 3). The mean difference between regurgitation fractions determined after an hour was $2 \%$ (limits of agreement $-7 \%$ to $10 \%$ ), and the corresponding value after 14 days was $1 \%$ (limits of agreement $-11 \%$ to $9 \%$ ) (fig 3 ).

Table 4 shows the values determined directly by the observers. A small but significant difference was found in the two observers' determinations of the left ventricular ejection fraction. None of the derived variables was significantly different, and the limits of agreement for the regurgitation fraction calculated by the two observers were $-9 \%$ to $9 \%$ (fig 4).

Figure 2 Haemodynamic variables while upright at rest and during

submaximal bicycle exercise in 10 patients with mitral regurgitation. Dashed lines indicate mean baseline values and bars $95 \%$ confidence intervals for differences.

\section{Discussion}

The severity of mitral regurgitation is dependent on the afterload that opposes left ventric-
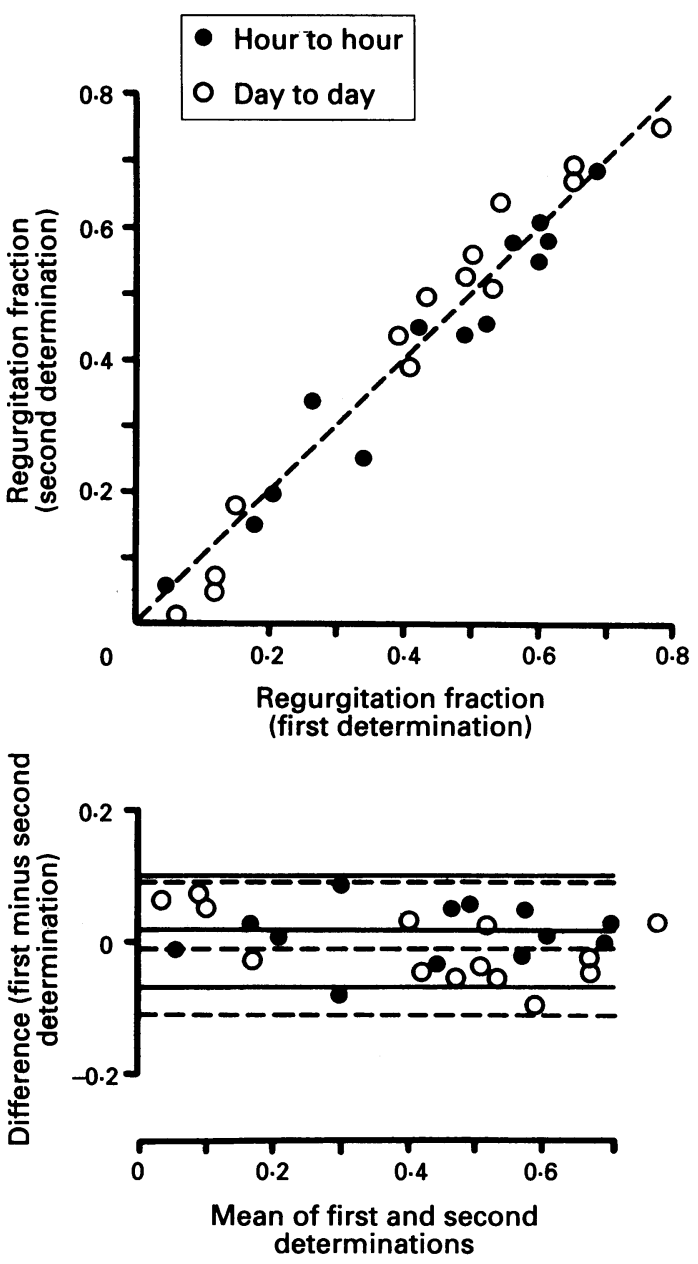

Figure 3 Repeatability of radionuclide determination of regurgitation fraction in patients with mitral regurgitation. Top: Correlation plot showing line of identity (-- - ). Bottom: Difference against mean plot showing mean values and limits of agreement corresponding to $1.96 S D$ between two determinations for hour to hour $(n=13)$ determinations (-) and day to day $(n=14)$ determinations (-- - ). ular ejection and on the systolic pressure gradient from the left ventricle to the left atrium. ${ }^{13-15}$ This gradient is most likely to increase when the patient stands up so the regurgitation fraction might be expected to be more pronounced while standing than while lying supine. The severity of regurgitation, however, would be expected to depend not only on left ventricular volumes but also on the nature of the underlying disease. Our results show that when the patients changed posture from supine to sitting upright, the changes in left ventricular volume were similar to those in healthy subjects. ${ }^{1617}$ The results also indicate that when the patients were examined as a group no significant alteration

Table 3 Hour to hour and day to day variation in mean (SD) values of haemodynamic variables at rest in 14 supine patients with mitral regurgitation

\begin{tabular}{|c|c|c|c|c|c|c|}
\hline & \multicolumn{3}{|c|}{ Hour to hour $(n=13)$} & \multicolumn{3}{|c|}{ Day to day $(n=14)$} \\
\hline & $\begin{array}{l}\text { First } \\
\text { determination }\end{array}$ & $\begin{array}{l}\text { Second } \\
\text { determination }\end{array}$ & $\begin{array}{l}\text { Limits of } \\
\text { agreement * }\end{array}$ & $\begin{array}{l}\text { First } \\
\text { determination }\end{array}$ & $\begin{array}{l}\text { Second } \\
\text { determination }\end{array}$ & $\begin{array}{l}\text { Limits of } \\
\text { agreement }\end{array}$ \\
\hline $\begin{array}{l}\text { Heart rate (beats } / \mathrm{min}) \\
\text { Blood pressure }(\mathrm{mm} \mathrm{Hg})\end{array}$ & $77(17)$ & $76(16)$ & -5 to 4 & $73(15)$ & $71(15)$ & -9 to 7 \\
\hline $\begin{array}{l}\text { Systolic } \\
\text { Diastolic } \\
\text { Left ventricular end diastolic } \\
\text { volume (ml) }\end{array}$ & $\begin{array}{r}127(25) \\
77(11) \\
222(81)\end{array}$ & $\begin{array}{l}128(25) \\
79(9) \\
217(77)\end{array}$ & $\begin{array}{c}-4 \text { to } 8 \\
-9 \text { to } 13 \\
-28 \text { to } 18\end{array}$ & $\begin{array}{l}121(19) \\
77(7) \\
241(70)\end{array}$ & $\begin{array}{l}124(19) \\
78(7) \\
239(71)\end{array}$ & $\begin{array}{l}-13 \text { to } 20 \\
-13 \text { to } 16 \\
-31 \text { to } 27\end{array}$ \\
\hline $\begin{array}{l}\text { Left ventricular ejection } \\
\text { fraction }(\%) \\
\text { Stroke volume }(\mathrm{ml}) \text { : }\end{array}$ & $55(19)$ & $55(19)$ & -3 to 3 & $54(20)$ & $54(20)$ & -4 to 4 \\
\hline $\begin{array}{l}\text { Total } \\
\text { Forward } \\
\text { Regurgitant volume (ml) }\end{array}$ & $\begin{array}{r}120(62) \\
60(23) \\
60(47)\end{array}$ & $\begin{array}{r}119(59) \\
62(22) \\
57(44)\end{array}$ & $\begin{array}{l}-17 \text { to } 14 \\
-6 \text { to } 9 \\
-20 \text { to } 14\end{array}$ & $\begin{array}{r}132(68) \\
64(21) \\
68(56)\end{array}$ & $\begin{array}{r}132(68) \\
62(18) \\
71(58)\end{array}$ & $\begin{array}{l}-14 \text { to } 14 \\
-16 \text { to } 12 \\
-11 \text { to } 18\end{array}$ \\
\hline
\end{tabular}

$\star 1.96 \mathrm{SD}$ of difference between first and second determination. 
Table 4 Observer variation in mean (SD) values of haemodynamic variables at rest in 20 supine patients with mitral regurgitation

\begin{tabular}{lccc}
\hline & Observer 1 & Observer 2 & Limits of agreement * \\
\hline Left ventricular end diastolic volume (ml) & $212(79)$ & $210(77)$ & -27 to 23 \\
Left ventricular ejection fraction $(\%)$ & $59(15)$ & $57(14)$ & -7 to $4 \dagger$ \\
Forward stroke volume (ml) & $57(16)$ & $55(16)$ & -10 to 6 \\
\hline
\end{tabular}

$\star_{1} .96$ SD of difference between observer 1 and observer 2 .

$+95 \%$ confidence interval of bias -3 to 0 . fraction, unaffected. The small increments in heart rate and diastolic blood pressure when our patients changed posture from supine to sitting upright were also indistinguishable from those reported in normal subjects. ${ }^{1617}$

In healthy subjects left ventricular end diastolic volume increases during mild to moderate exercise while the end systolic volume decreases. ${ }^{1920}$ The resultant increase in stroke volume is most pronounced at lower levels of work..$^{21}$ The cardiovascular response to exercise in cardiac disease has been most thoroughly investigated in patients with coronary artery disease. In most of these patients the left ventricle dilatates in response to exercise in the upright position, but, in contrast with the changes in healthy subjects, a dilatation is recorded both at end diastole and end systole, resulting in a smaller exercise induced increase or even a decrease in the left ventricular ejection fraction. ${ }^{22} 23$ Dehmer et al found that exercise induced end systolic dilatation was seen only in patients with disease of more than one vessel. ${ }^{24}$ Although the left ventricular ejection fraction was only slightly increased from rest to exercise in the 10 patients in our study, the forward stroke volume increased more obviously during exercise, the increase being considerably larger than that in total stroke volume.

The relation between preload and afterload of the left ventricle is probably particularly important for the severity of mitral regurgitation. In normal subjects the increase in left ventricular filling pressure as indicated by the pulmonary artery wedge pressure during exercise is more pronounced than the increase in systemic blood pressure. ${ }^{25}$ Similar findings were recorded in patients with coronary artery disease with and without moderate heart failure. ${ }^{26} 27$ Stevenson et al examined 10 patients with advanced heart failure (New York Heart Association functional class III to IV) and chronic mitral regurgitation using a combination of the thermodilution and radionuclide technique. ${ }^{28}$ They did not find any significant changes in either forward or total stroke volume during exercise before treatment, indicating that the increase in cardiac output during exercise was entirely attributable to a rise in heart rate. After tailored vasodilatation the exercise induced increase in cardiac output was also a result of a rise in forward stroke volume. Thus, exercise induced haemodynamic changes in patients with mitral regurgitation without signs of overt heart failure are similar to those recorded in normal subjects, and the severity of regurgitation is reduced during exercise.

The reproducibility of the determination of the regurgitation fraction using the combined radionuclide first pass and equilibrium technique was found to be high. The repeatability in terms of day to day variation was of the same magnitude as the hour to hour variation, the standard deviations of the difference being about 5\%. A small but significant difference was found in the two observers' measurements of the left ventricular ejection fraction, but the limits of agreement corresponded to 
those previously reported from our laboratory, with a standard deviation of the difference of $2.9 \% .^{8}$ Although radionuclide cardiography may not be the most widespread procedure for determining cardiac performance, it is highly reproducible, even in the upright position and during exercise. ${ }^{29}{ }^{30}$ In contrast with the combined radionuclide technique, measurements of mitral regurgitation from methods based on completely different principles, such as the thermodilution and radionuclide techniques in combination, may be influenced by tricuspid regurgitation. ${ }^{28}$ In addition, we used a radionuclide method to determine the regurgitation fraction, which has the advantage of reducing one of the key problems inherited in nuclear imaging - the subtraction of background activity - in that identical procedures for subtracting background are used in determining the forward and the total stroke volume. ${ }^{5}$

We emphasise that multigated cardiography is extremely troublesome in patients with cardiac arrhythmias and that the results of our study therefore apply primarily to patients with sinus rhythm. Thus, the findings of our study cannot uncritically be extrapolated to patients with atrial fibrillation, which is present in roughly $30 \%$ of patients with primary mitral regurgitation. ${ }^{13}$

In conclusion, left ventricular volumes are reduced in patients with clinically stable chronic mitral regurgitation when they change from lying supine to sitting upright. In patients with mitral valve prolapse and ruptured chordae regurgitation increases when sitting, whereas regurgitation is decreased in patients with ischaemic heart disease and dilated cardiomyopathy. Exercise in the upright position causes an increase in forward stroke volume and a decrease in the regurgitant volume, leading to a reduced regurgitation fraction. These results indicate that the severity of the disease is not worsened by exercise, provided that no symptoms are provoked.

1 Slater J, Gindea AJ, Freedberg RS, et al. Comparison of cardiac catheterization and Doppler echocardiography in the decision to operate in aortic and mitral valve disease. 7 Am Coll Cardiol 1991;17:1026-36.

2 Frankl WS. Valvular heart disease: the technologic dilemma. ₹ Am Coll Cardiol 1991;17:1037-8.

3 Cheitlin MD. Valvular heart disease: management and intervention. Circulation 1991;84(suppl I):I259-64.

4 Delahaye JP, Gare JP, Viguier E, Delahaye F, deGevigney $G$, Milon $H$. Natural history of severe mitral regurgitation. Eur Heart $\mathcal{F} 1991 ; 12$ (suppl B):5-9.

5 Kelbæk H, Aldershvile J, Svendsen JH, Folke K, Nielsen SL, Munck O. Combined first pass and equilibrium $\mathrm{SL}$, Munck $\mathrm{O}$. Combined first pass and equilibrium radionuclide cardiographic determination of stroke vol-
ume for quantitation of valvular regurgitation. $₹ \mathrm{Am}$ Coll ume for quantitation of

6 Kelbæk H, Bülow K, Aldershvile J, Møgelvang J, Nielsen SL. A new ${ }^{99 m}$ Tc-red blood cell labelling procedure fo cardiac blood pool imaging: clinical results. Eur $\mathcal{f} \mathrm{Nucl}$ Med 1989;15:333-5.

7 Kelbæk H, Hartling OJ, Skagen K, Munck O, Henriksen $\mathrm{O}$, Godtfredsen J. First-pass radionuclide determination of cardiac output: an improved gamma camera method. f Nucl Med 1987;28:1330-4.
8 Gjørup T, Kelbæk H, Vestergaard B, Fogh J, Munck O, Jensen AM. Reproducibility in the analysis of multigated radionuclide studies of left ventricular ejection fraction. Invest Radiol 1989;24:104-9.

9 Kelbæk H, Hartling OJ, Gjørup T, Marving J, Christensen NJ, Godtfredsen J. Effects of autonomic blockade on cardiac function at rest and during upright exercise in cardiac function at rest and during uprig
humans. F Appl Physiol 1987;63:554-7.

10 Gardner MJ, Altman DG. Confidence intervals rather than $P$ values: estimation rather than hypothesis testing. $B M F$ 1986;292:746-50.

11 Evans SJW, Mills P, Dawson J. The end of the $\mathrm{p}$ value? $\mathrm{Br}$ Heart 7 1988;60:177-80.

12 Bland JM, Altman DG. Statistical methods for assessing agreement between two methods of clinical measurement. Lancet 1986;i:307-10.

13 Corin WJ, Monrad ES, Murakami T, Nonogi H, Hess $\mathrm{OM}$, Krayenbuehl HP. The relationship of afterload to ejection performance in chronic mitral regurgitation. Circulation 1987;76:59-67.

14 Stevenson LW, Bellil D, Grover-McKay M, et al. Effects of afterload reduction (diuretics and vasodilators) on left ventricular volume and mitral regurgitation in severe congestive heart failure secondary to ischemic or idiopathic dilated cardiomyopathy. Am ₹ Cardiol 1987;60: 654-8.

15 Keren G, Bier A, Strom JA, Laniado S, Sonnenblick EH, LeJemtel TH. Dynamics of mitral regurgitation during nitroglycerin therapy: a Doppler echocardiographic study. Am Heart $\mathcal{F} 1986 ; 112: 517-25$.

16 Poliner LR, Dehmer GJ, Lewis SE, Parkey RW, Blomqvist CG, Willerson JT. Left ventricular performance in normal subjects: a comparison of the responses to exercise in the upright and supine positions. Circulation 1980; in the uprist

17 Manyari DE, Kostuk WJ, Purves PP. Left and right ventricular function at rest and during bicycle exercise in the supine and sitting positions in normal subjects and patients with coronary artery disease. $A m \mathcal{F}$ Cardiol 1983;51:36-42

18 Yoran C, Yellin EL, Becker RM, Gabbay S, Frater RWM, Sonnenblick EH. Mechanism of reduction of mitral regurgitation with vasodilator therapy. $A m \mathcal{f}$ Cardiol 1979;43:773-7.

19 Wyns W, Melin JA, Vanbutsele RJ, et al. Assessment of right and left ventricular volumes during exercise in normal men. Eur Heart f 1982;3:529-36.

20 Kelbæk H, Christensen NJ, Godtfredsen J. Left ventricular volumes during graded upright exercise in healthy untrained subjects. Clin Physiol 1988;8:51-6.

21 Sullivan MJ, Cobb FR, Higginbotham MB. Stroke volume increases by similar mechanisms during upright exercise in normal men and women. Am 7 Cardiol 1991;67: 1405-12.

22 Rerych SK, Scholz PM, Newman GE, Sabiston DC, Jones $\mathrm{RH}$. Cardiac function at rest and during exercise in normals and in patients with coronary heart disease. Ann Surg 1978;187:449-63.

23 Manyari DE, Kostuk WJ, Purves PP. Left and right ventricular function at rest and during bicycle exercise in the supine and sitting positions in normal subjects and papients with coronary artery disease. Am $\mathcal{f}$ Cardiol 1983; patients with

24 Dehmer GJ, Lewis SE, Hillis LD, Corbett J, Parkey RW, Willerson JT. Exercise-induced alterations in left ventricular volumes and the pressure-volume relationship: a sensitive indicator of left ventricular dysfunction in patients with coronary artery disease. Circulation 1981; 63:1008-18.

25 Higginbotham MB, Morris KG, Williams RS, McHale PA, Coleman RE, Cobb FR. Regulation of stroke volume during submaximal and maximal upright exercise in normal man. Circ Res 1986;58:281-91.

26 Shen WF, Roubin GS, Hirasawa K, et al. Left ventricular volume and ejection fraction response to exercise in chronic congestive heart failure: difference between dilated cardiomyopathy and previous myocardial infarction. Am ₹ Cardiol 1985;55:1027-31.

27 Kelbæk H, Heslet L, Skagen K, Christensen NJ, Godtfredsen J, Munck O. Hemodynamic effects of alcohol at rest and during upright exercise in coronary artery disease. Am 7 Cardiol 1988;61:61-4.

28 Stevenson LW, Brunken RC, Belil D, et al. Afterload reduction with vasodilators and diuretics decreases mitral regurgitation during upright exercise in advanced heart failure. $7 \mathrm{Am}$ Coll Cardiol 1990;15:174-80.

29 Kelbæk H, Giørup T, Hvid-Jacobsen K, Skagen K, Munck $\mathrm{O}$, Godufredsen $\mathrm{J}$, et al. Reliability of first-pass radionuclide determination of cardiac output in the uprigh position at rest and during exercise. Eur $\mathcal{F}$ Nucl Med
1992;19:955-9.

30 Kelbæk H, Gjørup T, Bülow K, Nielsen SL. Observer variability of radionuclide left ventricular volume determination at rest and during exercise. Acta Radiol 1993; 34:179-82. 